\title{
Green Drying: Continuous Dehumidified-Air Dryer
}

\section{L. Woo ${ }^{1, a}$, H. S. Yeoh ${ }^{2}$, S. K. Go ${ }^{1}$, and G. H. Chong ${ }^{1, b}$}

1 Department of Food Technology, Faculty of Food Science and Technology, Universiti Putra Malaysia, 43400 UPM, Serdang, Selangor, Malaysia.

2 Department of Chemical and Environmental, Faculty of Engineering, Universiti Putra Malaysia, 43400

UPM, Serdang, Selangor, Malaysia

E-mail: achyelin88@gmail.com, bgunhean@upm.edu.my (Corresponding author)

\begin{abstract}
Non-thermal drying, such as dehumidified-air drying has been introduced to overcome the drawbacks of conventional thermal and direct contact adsorption drying. However, existing approach of this method is not so user friendly as the dehumidifiedair cannot be supplied continuously due to the depletion of desiccants. The desiccants also need a high temperature for the regeneration. Therefore, a continuous dehumidified-air dryer is focused in this study. The dehumidified-air was produced alternately by adsorbents, which located in two chambers. The adsorbents were then regenerated at ambient temperature by pressure-swing concepts. This continuous dehumidified-dryer was commissioned by drying $A$. paniculata, at the dehumidified-air 10 to $30 \mathrm{~L} / \mathrm{min}$ and 30 to $50^{\circ} \mathrm{C}$. The sample was dried at less than 10 hours, and about $75 \%$ of andrographolide had been maintained. The Page model was well describing the drying behaviour, and the diffusivity coefficient was determined as $1.88 \times 10-13 \mathrm{~m}^{2} / \mathrm{s}$.
\end{abstract}

Keywords: Dehumidified-air, A. paniculata, drying, pressure-swing, drying kinetics.

ENGINEERING JOURNAL Volume 18 Issue 2

Received 9 July 2013

Accepted 1 October 2013

Published 18 April 2014

Online at http:/ /www.engj.org/

DOI:10.4186/ej.2014.18.2.119 


\section{Introduction}

Drying is the most common method used to extent the shelf life of biological product. A good drying process not only remove moisture but also maintain the nutrition value and give rise to other alterations that affect biological product's quality, such as changes in appearance and alterations in aroma.

Elevation of temperature is always used to accelerate the drying as the examples sun drying, even with the innovative methods such as roof-integrated solar drying [1], heat pump [2, 3], convective drying [4, 5], cabinet drying [6, 7], vacuum drying [8] and vacuum-microwave drying [9]. These approaches are not particularly suitable for the thermal labile material. This has encouraged researchers study on non-thermal drying such adsorption drying [10-13] and dehumidified-air convective drying [14]. However, the drying process needs to be halted when the adsorbents are exhausted with moisture. Therefore, this study is to address those drawbacks by incorporating a pressure swing adsorption dryer to produce dehumidified-air continuously. In the pressure swing system, partial of the dehumidified-air was used to contact the drying material and partially was used to regenerate the adsorbent. Andrographis paniculata is used to commission this continuous dehumidified-air dryer. A. paniculata which is known as hempedu bumi in Malaysia. Studies have shown that $A$. paniculata prevents the formation blood clots and that use of the herb prevents reclogging of arteries after angioplasty. It also has the potential benefits for treating cancer, human immunodeficiency virus (HIV) and other viruses [4].

\section{Materials and Methods}

\subsection{Materials}

Fresh $A$. paniculata were obtained from Malaysian Agricultural Research and Development Institute (MARDI, Serdang). The leaves together with stem were cut into 1.0-2.0 cm. The standard of andrographolide, $98 \%$ was purchases from Sigma-Aldrich, USA. Acetonitrile (HPLC grade) and Methanol (Analytical grade) were supplied by Merck (Darmstadt, Germany).

\subsection{Continuous Dehumidified-Air Drying}

Prior to drying experiments, about 30 minutes, the dryer was run to reach steady state condition at the desired operating conditions. The schematic diagram of the continuous dehumidified-air dryer is shown in Fig. 1. The air compressor (SVP202, Swan, Taiwan) (1) supplied air (6-4 bars) to the adsorption air dryer, which comprised of 2 chambers $(2,3)$ that contained adsorbents (molecular sieve, $3 \mathrm{~A}$ ) to pick up the moisture in the air. The regeneration of adsorbent was done through pressure swing at a cycle of 2 minutes, and the dehumidified-air (relative humidity $=0-1 \%$ ) was continuously supplied, this had been controlled by solenoid valves (2W030-08, Airtac, Taiwan) $(4,5)$. The dehumidified-air volumetric flow rate was controlled by a needle valve (6) and measured with a volumetric flow meter (822-2-OV1-PV1-V1MP-CRWM, Sierra, USA) (7). The temperature of dry air was adjusted by heater (8) and temperature controlling system (temperature controller (CH402, RKC, Japan), 9 and thermocouple, 12). As a safety fixture, a pressure switch (AP-C30W, Keyence, Japan) $(10,11)$ was used to disable the functionality of heater if the air pressure were not enough (less or no air was supplied). The drying materials, $A$. paniculata, $30.00 \pm 1.00 \mathrm{~g}$, were put in basket (15) and dried at drying chamber (volume of $1000 \mathrm{~mL}$ ) (14). The dehumidified-air was continuously passing through the drying materials and exited at (17) until the drying process was completed. The properties of air before and after contacting with drying materials were recorded by data loggers (13, 16) (EL-USB-2-LCD, Lascar, UK). The drying was continued until no different between the humidity of air before and after the drying sample.

The experiments were conducted with 30,40 and $50{ }^{\circ} \mathrm{C}$ and 10,20 , and $30 \mathrm{~L} / \mathrm{min}$ with three replicates for each treatment in order to verify the results obtained. 


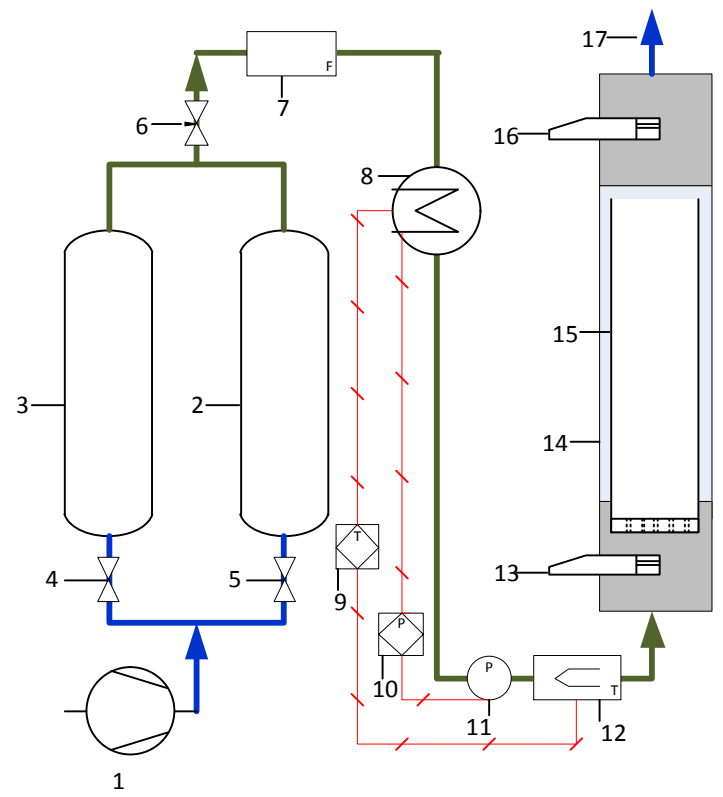

Fig. 1. Schematic diagram of continuous dehumidified-air dryer.

\subsection{Moisture Content Analysis}

Moisture content (MC) of fresh and dry $A$. paniculata was measured using a digital moisture analyser (Mettler Toledo, XM12D, Switzerland). This method was validated with the oven method for moisture determination AOAC official method 930.15 with $\pm 1-2 \%$ deviation. Approximately $0.50 \mathrm{~g}$ of the sample was cut into small pieces and placed over the tray of moisture analyser. The MC determination was completed when constant value was achieved. The MC of fresh and dry A. paniculata was expressed in percentage of a wet basis (wb). All the measurements were done in triplicate with adequate repeatability.

\subsection{Extraction of $A$. paniculata}

The extraction of andrographolide was done on fresh and dried $A$. paniculata. $3.0 \pm 1.0 \mathrm{~g}$ of fresh and dried $A$. paniculata was ground by using a blender. The ground $A$. paniculata was percolated with methanol overnight. Whatman No.1 filter paper was used to filter the solvent to produce the first part of methanol extract. The remaining marc was extracted again and overnight one more time in order to extract completely out the bioactive compound. Rotary evaporator (EYELA, N-1001S-WD, Japan) was used to remove approximately $90 \%$ of solvent from extract. The concentrated methanol extract was dried to yield the fully dried crude extract of $A$. paniculata in the oven $\left(30^{\circ} \mathrm{C}\right)$. The dried crude extract was stored at chiller of $4{ }^{\circ} \mathrm{C}$ until it was used for analysis.

\subsection{Determination of Andrographolide}

The content of andrographolide was determined by using the High Performance Liquid Chromatography (HPLC) [15]. The mobile phases used in this analysis were acetonitrile and water in a fraction of 7:3. The compounds were separated with a Restek HPLC C18 column, $5 \mu \mathrm{m}, 250 \mathrm{~mm}$ x $4.6 \mathrm{~mm}$ (Restek Chromatography, DB-C18, USA) and the column was maintained at $25^{\circ} \mathrm{C}$. The mobile phase was at 0.5 $\mathrm{mL} / \mathrm{min}$ and $15 \mathrm{~min}$ running time (501, Waters, USA). The diagnosis was operated at $230 \mathrm{~nm}$ using ultraviolet detector (486, Waters, USA). Known amount of crude extract was taken and dissolved it in the mobile phase to perform in $1.0 \mathrm{mg} / \mathrm{mL}$. The sample was filtered by syringe filter $(13 \mathrm{~mm}$ diameter, $0.2 \mu \mathrm{m}$ pore size, Nylon, Whatman, UK) before inject to HPLC. 


\subsection{Drying Kinetics}

The weights of the sample at the corresponded times were weighed and used to study the drying kinetics. The moisture ratio $(M R)$ and drying rate $(D R)$ of AP during drying were determined as

$$
\begin{gathered}
M R=\frac{M_{t}-M_{e}}{M_{o}-M_{e}} \\
D R=\frac{M_{t+d t}-M_{t}}{d t}
\end{gathered}
$$

where $M_{t}$ is the moisture content of the sample at any time, $M_{e}$ is the equilibrium moisture content, $M_{o}$ is the initial moisture content, $t$ is the drying time. However, the $M R$ was simplified to $M t / M o[16,17]$ because $M_{e}$ is relatively much smaller than $M_{t}$ and $M_{0}$.

The thin layer empirical and semi-empirical mathematical models (Table 1) were evaluated to determine the best model for describing the drying kinetics of $A$. paniculata. By using SOLVER, an optimization tool in Microsoft Excel 2007, the parameters of the different models were determined. The coefficient determination $\left(\mathrm{R}^{2}\right)$ was used as the criterion for choosing the best model to describe the drying curve. In addition, root mean square error (RMSE) was used to determine the quality of the fit.

$$
R M S E=\left[\frac{1}{N} \sum_{i=1}^{N}\left(M R_{c a l, i}-M R_{\text {exp }, i}\right)^{2}\right]^{\frac{1}{2}}
$$

\begin{tabular}{|c|c|c|c|}
\hline Model name & Model & & Reference \\
\hline Newton & $M R=\exp (-k t)$ & (4) & [18] \\
\hline Page & $M R=\exp \left(-k t^{n}\right)$ & (5) & [19] \\
\hline Henderson and Pabis & $M R=a \exp (-k t)$ & (6) & {$[20]$} \\
\hline Logarithmic & $M R=a \exp (-k t)+c$ & (7) & {$[21]$} \\
\hline Two-term & $M R=a \exp (-k t)+b \exp \left(-k_{o} t\right)$ & (8) & [22] \\
\hline Two-term exponential & $M R=a \exp (-k t)+(1-a) \exp (-k a t)$ & (9) & [23] \\
\hline Fick's second law & $M R=\frac{6}{\pi^{2}} \sum_{i=1}^{i=\infty} \frac{1}{i^{2}} \exp \left[-i^{2} \pi^{2}\left(\frac{D_{e f f} t}{L^{2}}\right)\right]$ & $(10)$ & [24] \\
\hline
\end{tabular}

where $M R_{\text {cal } i}$ is the $i$ th calculated moisture ratio, $M R_{\text {exp }, i}$ is the $i$ th experimental moisture ratio.

Table 1. Selected empirical and semi-empirical models for thin-layer drying.

Note: $\quad a, b, c=$ coefficient; $k, k_{o}=$ drying constant; $L=$ half thickness of slab (m).

\subsection{Statistical Analysis}

Experimental data are presented as mean values with standard deviations. Values were considered significant at $\mathrm{p}<0.05$, and a statistical program, Minitab 14 (Minitab Inc., USA) was used to perform the calculations. 


\section{Results and Discussion}

\subsection{Effect of Drying Conditions on Drying Time}

As shown in Table 2, the dehumidified-air dryer able to dry the sample in ambient temperature $\left(30{ }^{\circ} \mathrm{C}\right)$ at drying time less than 23 hours. From the previous experience, the completion of drying takes few days for the conventional air drying. This enhancement could be explained as the dehumidified-air, which is in extremely low humidity provoke the mass transfer. The moisture transfer rate was faster when dehumidified-air flow rate increased. This might due to the replacement of moist air is relatively faster at higher flow rate, in which maintain the higher drying force. This observation is same as the finding from Ahmadi Chenarbon et al. [25] who does on hot air drying of herbal leaves.

The findings also showed that drying time became shorter as the temperature of dehumidified-air increased and it is common finding observed by other researchers [26, 27].This is because an extra energy is provided to the drying process that increases the moisture transfer, especially to the bound water transferring.

Table 2. Drying time (hour) at different temperatures and air flow rates.

\begin{tabular}{lccc}
\hline \multirow{2}{*}{ Air Flow, L/min } & \multicolumn{3}{c}{ Temperature, ${ }^{\circ} \mathrm{C}$} \\
\cline { 2 - 4 } & 30 & 40 & 50 \\
\hline $10(1 \% \mathrm{RH})$ & $22.50^{\mathrm{cz}} \pm 0.71$ & $17.50^{\mathrm{bz}} \pm 0.71$ & $15.50^{\mathrm{ay}} \pm 0.71$ \\
$20(1 \% \mathrm{RH})$ & $15.50^{\mathrm{cy}} \pm 0.50$ & $8.90^{\mathrm{by}} \pm 0.57$ & $7.23^{\mathrm{ax}} \pm 0.25$ \\
$30(1 \% \mathrm{RH})$ & $9.35^{\mathrm{cx}} \pm 0.49$ & $7.47^{\mathrm{bx}} \pm 0.50$ & $6.63^{\mathrm{ax}} \pm 0.51$ \\
\hline
\end{tabular}

Note: $\quad$ The average final moisture content of sample was $6.41 \pm 0.97 \%$ (wet basis). Values were expressed as mean \pm standard deviation.

$a-b$ Means with the different letter within same row were significant different at the level $p<0.05$. $x-z$ Means with the different letter within same column were significant different at the level $p<0.05$.

\section{2. $\quad$ Effect of Drying Conditions on Andrographolide}

The quality of $A$. paniculata was evaluated based on the remainder of bioactive compound of the dried samples by using HPLC as the comparative analysis and the average andrographolide in fresh sample was around $0.1798 \mathrm{mg}$ per $\mathrm{mg}$ of dried crude extract. From the results obtained (Table 3), there was a trend in which with increasing drying temperature, the percentage loss of andrographolide contents increased. This observation is in agreement with Rocha et al. [28] that drying temperatures is the most influential variable to preserve the active ingredients of medicinal plants. On the other hand, there was no clear trend for percentage loss of andrographolide contents with increasing drying air flow rate.

Table 3. Percentage loss of andrographolide.

\begin{tabular}{llll}
\hline \multirow{2}{*}{ Air Flow, L/min } & \multicolumn{3}{c}{ Temperature, ${ }^{\circ} \mathbf{C}$} \\
\cline { 2 - 4 } & \multicolumn{1}{c}{$\mathbf{3 0}$} & \multicolumn{4}{c}{$\mathbf{4 0}$} & $\mathbf{5 0}$ \\
\hline 10 & $38.40^{\text {ay }} \pm 0.77$ & $47.16^{\text {bx }} \pm 0.27$ & $48.99^{\text {cx }} \pm 0.62$ \\
20 & $37.89^{\text {axy }} \pm 11.76$ & $54.90^{\text {by }} \pm 4.02$ & $53.48^{\text {by }} \pm 1.13$ \\
30 & $25.39^{\text {ax }} \pm 7.96$ & $52.90^{\text {by }} \pm 2.05$ & $54.67^{\text {by }} \pm 4.31$ \\
\hline
\end{tabular}

Note: $\quad a, b, c$ Means with the different letter within same row were significant different at the level $p<0.05$.

$x, y, z$ Means with the different letter within same column were significant different at the level $p<0.05$.

\subsection{The Appropriate Adsorption Drying Condition of A. paniculata}

From the effect of different drying conditions on drying time, the drying condition of $50{ }^{\circ} \mathrm{C}, 30 \mathrm{~L} / \mathrm{min}$; $50{ }^{\circ} \mathrm{C}, 20 \mathrm{~L} / \mathrm{min}, 40{ }^{\circ} \mathrm{C}, 30 \mathrm{~L} / \mathrm{min} ; 40{ }^{\circ} \mathrm{C}, 20 \mathrm{~L} / \mathrm{min}$; and $30{ }^{\circ} \mathrm{C}, 30 \mathrm{~L} / \mathrm{min}$ the drying times were less than 10 hours. While, drying condition of $30^{\circ} \mathrm{C}, 30 \mathrm{~L} / \mathrm{min}$ was the most appropriate to use since the loss of andrographolide content was the least. Furthermore, the low temperature used also results in a significant reduction in energy consumption per $\mathrm{kg}$ of moisture removed [9]. 


\subsection{Drying Kinetics}

The drying behaviour of the appropriate drying conditions $\left(30^{\circ} \mathrm{C}, 30 \mathrm{~L} / \mathrm{min}\right)$ was studied more detail and illustrated in Fig. 2. It could be seen that, the moisture content reduced continually with the drying time. This drying behaviour was fitted remarkably well with Page model $\left(\mathrm{R}^{2}=0.9992\right.$, Table 4$)$ as shown in Figure 2. There was no constant drying rate (Fig. 2), which usually found many drying process. Apparently, drying seems to be taken place at falling drying period. This could be due to the rapid moisture removal from the surface of the $A$. paniculata and showed the diffusion-dominant drying phenomena [21]. The diffusivity coefficient was determined as $1.88 \times 10^{-13} \mathrm{~m}^{2} / \mathrm{s}$ by using Fick's second law.

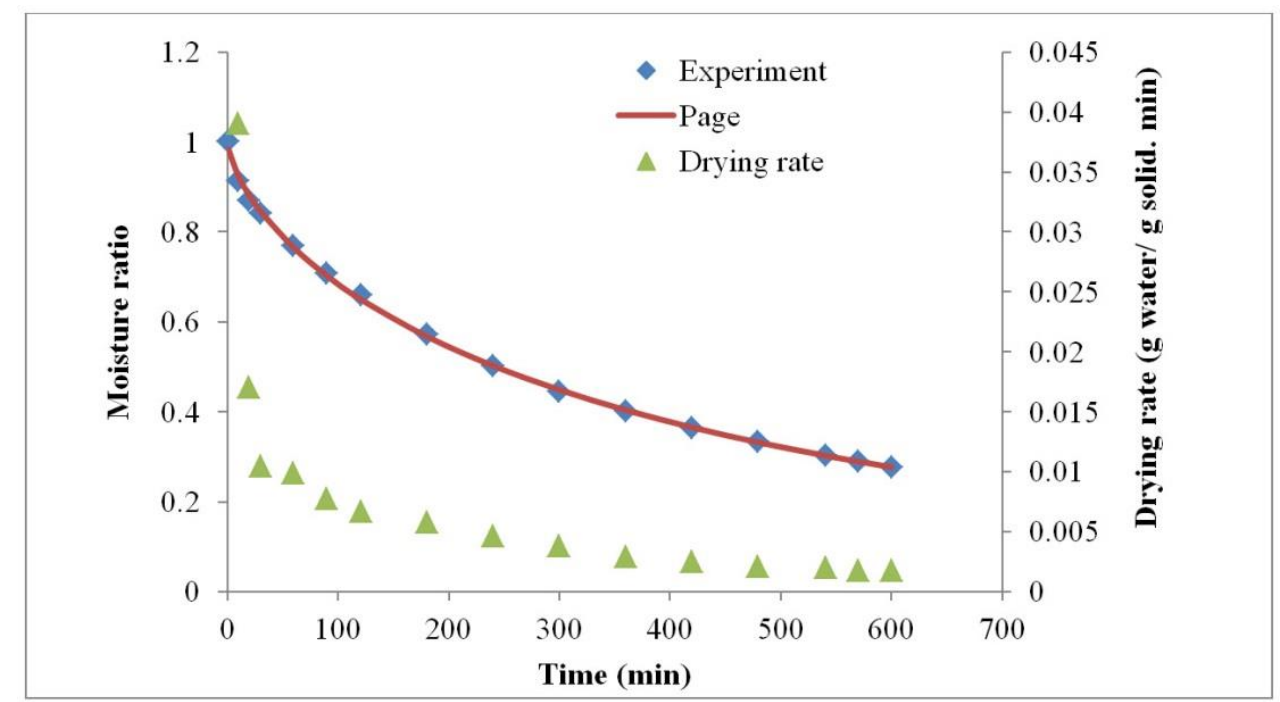

Fig. 2. Drying bahaviour, curve fitting (left axis) and drying rate (right axis) at $30^{\circ} \mathrm{C}, 30 \mathrm{~L} / \mathrm{min}$.

Table 4. Fitting of various thin layer drying model.

\begin{tabular}{llr}
\hline Model name & $\mathbf{R}^{\mathbf{2}}$ & $\mathbf{R M S E}$ \\
\hline Newton & 0.9571 & 0.05938 \\
Page & 0.9992 & 0.00667 \\
Henderson and Pabis & 0.9797 & 0.03509 \\
Logarithmic & 0.9942 & 0.01825 \\
Two-term & 0.9978 & 0.01137 \\
Two-term exponential & 0.9839 & 0.03375 \\
Approximation of diffusion & 0.9975 & 0.01196 \\
Modified Henderson and Paris & 0.9971 & 0.01294 \\
Fick's second law & 0.9860 & 0.02556 \\
\hline
\end{tabular}

\section{Conclusions}

The dehumidified-air dryer was successfully commissioned as to dry $A$. paniculata. The dryer dried the sample at ambient temperature for less than 10 hours. The drying time was affected by temperature and air flow rate. However, the percentage reduction of andrographolide was only reduced as the temperature increased. As an appropriate drying conditions for $A$. paniculata by using continuous dehumidified-air dryer, $30^{\circ} \mathrm{C}$ and $30 \mathrm{~L} / \mathrm{min}$ was suggested. The Page model was well describing the drying behaviour, and the diffusivity coefficient was determined as $1.88 \times 10^{-13} \mathrm{~m}^{2} / \mathrm{s}$. 


\section{Acknowledgement}

The authors would like to acknowledge the financial support from Universiti Putra Malaysia through Research University Grant Scheme (Vot no. 9300360).

\section{References}

[1] S. Janjai , N. Srisittipokakun, and B. K. Bala, "Experimental and modelling performances of a roofintegrated solar drying system for drying herbs and spices," Energy, vol. 33, pp. 91-103, 2008.

[2] J. C. Atuonwu, X. Jin, Gv. Straten, H. Cv. Deventer, and J. Bv. Boxtel, "Reducing energy consumption in food drying: Opportunities in desiccant adsorption and other dehumidification strategies," Procedia Food Science, vol. 1, pp.1799-1805, 2011.

[3] M. Fatouh, M. N. Metwally, A. B. Helali, and M. H. Shedid, "Herbs drying using a heat pump dryer," Energy Conversion and Management, vol. 47, pp. 2629-2643, 2006.

[4] A. Kaya and O. Aydin, "An experimental study on drying kinectics of some herbal leaves," Energy Conversion and Management, vol. 50, pp. 118-124, 2009.

[5] M. S. Sagrin and G. H. Chong, "Effects of drying temperature on the chemical and physical properties of Musa acuminata Colla (AAA Group) leaves," Industrial Crops and Products, vol. 45, pp. 430-434, 2013.

[6] J. Ahmed, U. S. Shivhare, and G. Singh. "Drying characteristics and product quality of coriander leaves," Food and Bioproducts Processing, vol. 9, pp. 103-106, 2001.

[7] I. Doymaz, N. Tugrul, and M. Pala. "Drying characteristics of dill and parsley leaves," Journal of Food Engineering, vol. 77, pp. 559-565, 2006.

[8] C. R. Nor, M. N. Ibrahim, and S. T. Song, "Preliminary studies on vacuum drying of Hempedu Bumi (Andrographis Paniculata)," in Proceedings of Regional Engineering Postgraduate Conference, 2009.

[9] A. Calin-Sanchez, A. Szumny, A. Figiel A, K. Jaloszynski, M. Adamski, and A. A. CarbonellBarrachina, "Effects of vacuum level and microwave power on rosemary volatile composition during vacuum-microwave drying," Journal of Food Engineering, vol. 103, pp. 219-227, 2011.

[10] O. Guillermo, G. Tzayhri, L. Socorro, and A. Sofia, "Immersion drying of wheat using al-pilc, zeolite, clay, and sand as particulate media," Drying Technology, vol. 24, pp. 1033-1038, 2006.

[11] R. G. Suhas and S. C. Manjeet, "Pecan drying with silica gel," Energy in Agriculture, vol. 2, pp. 11-20, 1983.

[12] W. Kittisak, P. Somkiat, N. Adisak, and S. Somchart, "Multi-pass sorption drying of paddy using rice husk adsorbent: experiments and simulation," Dairy Technology, vol. 27, pp. 226-236, 2009.

[13] Z. Y. Li, K. Noriyuki, W. Fujio, and H. Mananobu, "Sorption drying of soybean seeds with silical gel," Drying Technology, vol. 20, pp. 223-233, 2002.

[14] M. Djaeni, P.V. Bartels, C. J. van Asselt, J. P. M. Sanders, G. van Straten, and A. J. B. van Boxtel, "Assessment of a two-stage zeolite dryer for energy-efficient drying," Drying Technology, vol. 27, pp. 1205-1216, 2009.

[15] D. C. Jain, M. M. Gupta, S. Saxena, and S. Kumar, "LC analysis of hepatoprotective diterpenoids from Andrographis paniculata" Journal of Pharmaceutical and Biomedical Analysis, vol. 22, pp. 705-709, 2000.

[16] S. Kayisoglu and C. Ertekin, "Vacuum Drying Kinetics of Barbunya Bean (Phaseolus vulgaris L. elipticus Mart.)," The Philippine Agricultural Scientist, vol. 94, pp. 285-291, 2011.

[17] J. Mitra, S. L. Shrivastava, and P. S. Rao, "Vacuum dehydration kinetics of onion slices," Food and bioproducts processing, vol. 89, pp.1-9, 2011.

[18] J. R. O'Callaghan, D. J. Menzies, and P. H. Bailey, "Digital simulation of agricultural drier performance," Journal of Agricultural Engineering Research, vol. 16, pp. 223-244, 1971.

[19] G. Page, Factors Influencing the Maximum Rates of Air-Drying Shelled Corn in Thin Layer. West Lafayette: Purdue University, 1949.

[20] S. M. Henderson and S. Pabis, "Grain drying theory. II. Temperature effects on drying coefficients," Journal of Agricultural Engineering Research, vol. 6, pp. 169-174, 1961.

[21] J. H. Lee and H. J. Kim, "Vacuum drying kinetics of Asian white radish (Raphanus sativus L.) slices," LWT - Food Science and Technology, vol. 42, pp. 180-186, 2009.

[22] S. M. Henderson, "Progress in developing the thin-layer drying equation," Transactions of the ASAE, vol. 17, pp. 1167-72, 1974. 
[23] Y. I. Sharaf-Eldeen, J. L. Blaisdell, and M. Y. Hamdy, "A model for ear-corn drying," Transactions of the ASAE, vol. 23, pp.1261-1265, 1980.

[24] J. Crank, The Mathematics of Diffusion. Oxford: Clarendon Press, 1975.

[25] H. Ahmadi Chenarbon, S. Minaei, A. R. Bassiri, M. Almassi, and A. Arabhosseini, "Effective parameters on drying of Hypericum perforatum L. Leaves," Journal of Medicinal Plants Research, vol. 5, pp. 4530-4536, 2011.

[26] P. S. Madamba and R. P. Yabes, "Determination of the optimum intermittent drying conditions for rough rice (Oryza sativa, L.)," Lebensmittel - Wissenschaft \& Technologie, vol. 38, pp.157-165, 2005.

[27] S. Abdullah, M. S. Ahmad, A. R. Shaari, H. M. Johar, and N. F. M. Noor, "Drying characteristics and herbal metabolites composition of misai kucing (Orthosiphon staminiues Benth.) leaves," in Proceedings of International Conference on Food Engineering and Biotechnology, Singapore, 2011, pp. 305-9.

[28] R. P. Rocha, E. C. Melo, and L. L. Radunz, "Influence of drying process on the quality of medicinal plants: A review," Journal of Medicinal Plants Research, vol. 5, pp. 7076-7084, 2011. 